ORIGINAL RESEARCH PAPER

\title{
ISOLATION AND CHARACTERIZATION OF A MICROBIAL PIGMENT OBTAINED FROM SERRATIA MARCESCENS AS A NATURAL FOOD COLOURANT
}

\author{
SHARMISTA GAJADHAR, JOHN JASON MELLEM* \\ ${ }^{I}$ Department of Biotechnology and Food Technology, Durban University of Technology, Durban \\ 4000, South Africa \\ *Corresponding author: johnm@dut.ac.za
}

Received on 12 October 2018

Revised on 6 May 2019

\begin{abstract}
The use of naturally sourced pigments in the food industry is limited due to their instability when exposed to processes and parameters such as light, $\mathrm{pH}$, and high temperatures. Research has moved towards exploiting pigmented microorganism as sources of potential natural colorants, with the color red representing the largest market segment in the color industry, utilized in various food applications. This study was aimed isolation and characterization of Prodigiosin obtained from Serratia marcescens for potential application as a food colorant. Optimization results were achieved by cultivation in lysogeny broth $(\mathrm{Lb})$ at $25^{\circ} \mathrm{C}$ for a duration of $120 \mathrm{~h}$ at $\mathrm{pH} 6.5$, prodigiosin showed a gradual reduction in $\mathrm{pH}$ stability as well as a rapid change in color upon the addition of respective buffers due to protonation and deprotonation of respective groups. Instability to light due to chemical reaction such as oxidation and metal ion loss and instability at high temperatures was due to destruction of pyrrole group which is responsible for the reddish characteristic color. Results concluded that prodigiosin would be more applicable for utilization as a colorant in food applications within a temperature range of 0 to $20^{\circ} \mathrm{C}$ and $\mathrm{pH}$ of range 2 to 7 .
\end{abstract}

Keywords: Prodigiosin, Serratia marcescens, pigment stability

\section{Introduction}

An existent problem in the food industry is the limitation of naturally derived red colorants that are stable when exposed to processing parameters such as heat or $\mathrm{pH}$ (Nachay, 2014). Color is suggested to play a crucial role in determining both the quality and acceptability of foods and beverages. Due to legislative demand and consumer concerns regarding synthetic colorings, the demand for naturally derived colorants has increased. Although red is suggested to be a complex color to produce, it occupies the majority share in the color segment of the market (Dabas and Kean, 2014).

https//doi.org/10.35219/foodtechnology.2019.1.11 
While there is an increased demand for natural colorants, they were found to display less stability when exposed to light, temperature and $\mathrm{pH}$ (Malik et al., 2012). The two-basic sources from which natural color can be derived are plants and microorganisms. However, previous studies utilizing bio-colorants from plant sources depict various levels of instability when exposed to different processing parameters. Anthocyanins were found to exhibit instability when exposed to $\mathrm{pH}>4.5$, above the $\mathrm{pH}$ range the pigment changes hue from red to blue and were deemed unsuitable for acidic applications.

Betanin also commonly known as beetroot red is a root crop which is consumed globally. The red colorant obtained from betanin significantly degrades when exposed to parameters such as light, heat, and oxygen (Chandran et al., 2014). Alternatively, carmine derived from cochineal insects was proposed, however due to the extract possessing proteins, it was considered hazardous to humans with the potential to cause severe allergic reactions and was ruled out by regulatory bodies. Thus, the need for a natural, stable, cost-effective and clean-labelled red colorant occurred. The aim of the study was to isolate and characterize pigment isolated from $S$. marcescens strain with potential utilization in a food product as a natural colorant in order to optimise growth conditions for increased yield and pigment quality from $S$. marcescens, to determine the stability of the extracted pigment against $\mathrm{pH}$; temperature; light and degradation kinetics and to apply the colorant to a food product.

Various microorganisms have the ability to produce arrays of pigments and have potential to be utilized as natural food colorants (Malik et al., 2012). Pigments obtained from microbes are considered advantageous in comparison to synthetic colors or pigments sourced from plants due to efficient processes of production (Kumar et al., 2015). As proposed by Dufossé et al. (2005), the cultivation and growth of microorganisms can be facilitated on relatively cheap culture media as they are independent of climatic conditions. Aside from the array of shades, microbial pigments are considered biodegradable and environment-friendly. Microbial pigments have been observed to have medical and clinical potential such as antioxidant potential, immunosuppressive properties, and utilization as treatment for diabetes mellitus and cancer (Kumar et al., 2015). The most common microorganisms capable of pigment production are fungi; yeast; algae and bacteria.

Since microorganisms adversely have more versatility and productivity than any other forms of life, encompassing relatively large gene strands, research such as genetic engineering enables manipulation to generate increased pigment production. Research and development of microbial pigments are relatively new, thus there are many opportunities to further source, cultivate and reproduce stable natural colorants acceptable for industrial production (Kumar et al., 2015).

Serratia marcescens is an opportunistic Gram-negative bacillus and is a member of the Entrobacteriaceae group. S. marcescens pigment-producing bacterium can be sourced from ecological niches such as soil, plants, water, air, and in animals (Boone and Castenholz, 2001). Previous research is indicative of S. marcescens extracellular enzyme efficacy; these enzymes depict abilities of the destruction of 
chitin which mainly comprises in the cell walls of fungi. Chitinolytic enzymes possess potential for both industrial and agricultural application. Scientific literature present that Serratia marcescens produces color varying pigmentation such as red, white and pink as a function of temperature, nutrient content in media, and contact with ultraviolet light (El-Bialy and El-Nour, 2015).

Prodigiosin is a pigment that can be sourced from microorganism (Khanafari et al., 2006): Serratia marcescens, Vibrio psychoeytrus, Rugamonas rubra and Streptoyverticillum rubrireticuli. Prodigiosin is a secondary metabolite that exhibits a distinctive red color. It was reported to have no direct role in development or reproduction of the cell; however it was suggested to serve as a defence mechanism. Structurally, prodigiosin belongs to the chemical family of tripyrrole which was reported to contain a common 4-methoxy, 2-2 bipyrrole ring. The synthesis of the pigment is suggested to be made up of two pathways, where mono and bipyrrole precursors are separately synthesized and then combined to form prodigiosin (Boger and Patel, 1988). The production of the pigment was suggested to essentially vary depending on the species type, duration of incubation and temperature (Giri et al., 2004). Prodigiosin is said to have and exhibit antifungal, antibacterial, and antiprotozoal activities (Moraes et al., 2009). It is also considered to be antimalarial, antibiotic, immunosuppressive and anticancer (Suryawanshi et al., 2014). These properties make prodigiosin research appealing. Montaner et al. (2000) examined the effects of prodigiosin on haematopoietic cancer cells and assessed for possible cytotoxic activity. The study concluded that prodigiosin has potential in being utilized as an anticancer drug. The prodigiosin pigment was characterized and the ability to dye different fabrics tested. Therefore, the application behind the experimental design targeted the textile industry. Many theories support the use of prodigiosin in the medical field as prodigiosin depicts many therapeutic attributes. However it's potential to be utilized as a natural colorant in foods has yet to be explored. This study attempted to determine the extracted pigments stability potential and its suitability as a natural colorant when applied to a food product.

\section{Materials and methods}

\section{Optimization of Bacterial Growth}

A strain of Serratia marcescens was obtained from the Durban University of Technology, Microbiology Laboratory. The strain was preserved by preparing an overnight liquid culture incubated at $28^{\circ} \mathrm{C}$ for $18 \mathrm{~h}$, thereafter $500 \mu \mathrm{L}$ of the overnight liquid culture with an absorbance of $0.6 \mathrm{OD}_{600}$ was transferred into $2 \mathrm{~mL}$ cryovial tube containing $500 \mu \mathrm{L}$ of $50 \%$ glycerol. The prepared stock culture was stored at $-80^{\circ} \mathrm{C}$. Growth of Serratia marcescens was observed by transferring a full loop inoculum into a $50 \mathrm{~mL}$ flask containing nutrient broth (Sigma-Aldrich). The inoculum was incubated at $28^{\circ} \mathrm{C}$ for $24 \mathrm{~h}$ (exponential phase). Following incubation, $1 \mathrm{~mL}$ of a $0.6 \mathrm{OD}_{600}$ inoculum was transferred into $100 \mathrm{~mL}$ nutrient broth. Growth of the bacteria was observed over a duration of $24 \mathrm{~h}$ to observe when pigment production becomes visible. Optimization was carried out using the 
method of Ramani et al. (2014) with modifications. As per literature the following factors: $\mathrm{pH}$, duration, temperature, and selective media play a role in influencing pigment production in $S$. marcescens. Thus, optimization was conducted capitalizing on the various mentioned factors. Media that was selected for the optimization was nutrient broth and lysogency broth (Lb) (Casullo de Araújo et al., 2010).

The $\mathrm{pH}$ of the media were adjusted to the $\mathrm{pH}$ values of 4, 6, 5, 7, and 9 units utilizing $1 \mathrm{M}$ of Hydrochloric acid $(\mathrm{HCl})$ and $1 \mathrm{M}$ of Sodium hydroxide $(\mathrm{NaOH})$ with the control being at $\mathrm{pH}$ 7. According to a study conducted by Das et al. (2018), S. marcescens depicted viability in $\mathrm{pH}$ ranging from 5 to 9 , however the production of prodigiosin was only noted in $\mathrm{pH}$ ranging between 5 to 8 . A study conducted by Elkenawy et al. (2017) revealed that pigment production was higher at $\mathrm{pH} 9$ in comparison to $\mathrm{pH}$ 5. Since $\mathrm{pH}$ plays a crucial role in the development of prodigiosin, the study focused on utilizing a broader $\mathrm{pH}$ range to justify the effect of $\mathrm{pH}$ on pigment production. One $\mathrm{mL}$ of $0.6 \mathrm{OD}_{600}$ inoculum was transferred aseptically into flasks containing $100 \mathrm{~mL}$ of nutrient broth and lysogeny broth followed by incubation at the 25 and $30^{\circ} \mathrm{C}$ for $120 \mathrm{~h}$. According to a study conducted by Williams et al. (1971), the production of prodigiosin is favoured between $25-28^{\circ} \mathrm{C}$, over a 7 day period. Casullo de Araújo et al. (2010) found that at temperatures exceeding $30^{\circ} \mathrm{C}$, pigment production in Serratia marcescens ceased, and colonies were characteristically creamy white in color. This observation suggested that at temperatures exceeding $30^{\circ} \mathrm{C}$ there is a possible loss in enzyme activity, which results in no prodigiosin production.

Observations were made at the following intervals: 24, 48, 72, 96 and $120 \mathrm{~h}$. Estimation of prodigiosin was obtained utilizing a formula by Mekhael and Yousif (2009) as presented in equation 1. The absorption of the bacterial cells was observed prior to extraction. The observations were carried out at the mentioned respective intervals.

$$
\text { Prodigiosin unit } / \text { cell }=\frac{O D 533-(1.381 \times O D 600)] \times 1000}{O D 600}
$$

$\mathrm{OD}_{533}$ is optical density of the prodigiosin at $\lambda=533 \mathrm{~nm}$

$\mathrm{OD}_{600}$ is optical density of the bacterial cells at $\lambda=600 \mathrm{~nm} ; 1.381$ is a constant

\section{Extraction of pigment}

Cultivation and isolation was carried out as per optimization results obtained. Pigment extraction was carried out utilizing the method by Nakashima et al. (2005) with modifications. In this study, the type of media and period of incubation differed. Serratia marcescens was cultivated in $100 \mathrm{~mL}$ lysogeny broth $(\mathrm{Lb})$ at $28^{\circ} \mathrm{C}$ for $96 \mathrm{~h}$. An equal volume of methanol was added and the mixture was vortexed. After centrifugation at $10000 \times \mathrm{g}$ for $30 \mathrm{~min}$, the pellet was discarded and the supernatant evaporated at $45-50^{\circ} \mathrm{C}$. Then, $10 \mathrm{~mL}$ of chloroform was added with the addition of $95 \%$ ethanol:water in the ratio of $1: 4(\mathrm{v} / \mathrm{v})$. The resultant mixture was freeze-dried to evaporate the solvents and obtain the powered pigment. A presumptive test was conducted as per Ding and Williams (1983), by the addition 
of $1 \mathrm{M} \mathrm{HCl}$ or alternatively $1 \mathrm{M}$ of $\mathrm{NaOH}$ in crude pigment indicating the presence of prodigiosin upon a distinctive color change.

UV-VIS analysis was conducted on the extracted pigment by dissolving it in methanol (Vora et al., 2014). The scan was conducted between 200 to $800 \mathrm{~nm}$, to determine the maximum absorbance spectra. In this case the blank was methanol.

\section{Purification by thin layer chromatography (TLC)}

Thin layer chromatography was preformed utilizing the method by Vora et al. (2014). The extracted pigment was dissolved in methanol and then applied by a capillary tube on silica gel. Chloroform:methanol $(95: 5 \mathrm{v} / \mathrm{v})$, was the solvent system used. The chamber and system were kept for $20 \mathrm{~min}$ until equilibration. The sheet was removed and thereafter air dried. The retention factor (RF) was calculated using equation 2 :

$$
R f=\frac{\text { Distance travelled by the compound }}{\text { Distance travelled by the solvent front }}
$$

\section{Pigment stability}

Evaluation of $\mathrm{pH}$ stability

To evaluate extracted pigment stability, the extracted pigment was exposed to various $\mathrm{pH}$ values and was conducted in accordance to the method by Namazkar and Ahmad (2013). The crude pigment $(100 \mathrm{mg} / \mathrm{L}$ in methanol) was recorded by varying the $\mathrm{pH}$ between 2 and 11 utilizing $1 \mathrm{M}$ of $\mathrm{NaOH}$ or $1 \mathrm{M}$ of $\mathrm{HCl}$ buffers to achieve the required $\mathrm{pH}$ range. $\mathrm{pH} 7$ was utilized as a control and observations were conducted over a duration of $120 \mathrm{~h}$. Absorbance was recorded utilizing wavelength $\lambda=200-800 \mathrm{~nm}$ at intervals $0 ; 24 ; 48 ; 72 ; 96$; and $120 \mathrm{~h}$.

\section{Evaluation of temperature stability}

To observe the effect of temperature on the pigment, $10 \mathrm{~mL}$ of crude pigment $(100$ $\mathrm{mg} / \mathrm{L}$ in methanol) was dispensed into test tubes and kept in a water bath at various temperatures ranging between $20,40,60$, and $80^{\circ} \mathrm{C}$. The absorbance was read at 20 minute intervals for a duration of $120 \mathrm{~min}$.

\section{Evaluation of light stability of pigment}

Extracted pigments response to light stability was evaluated utilizing the method by Namazkar and Ahmad (2013). A quantity of $10 \mathrm{~mL}$ of crude pigment $(100 \mathrm{mg} / \mathrm{L}$ in methanol) was dispensed into test tubes and exposed to fluorescent light at 1.5 meters away from the source. Positive control was stored in the absences of light. Absorbance was measured at $533 \mathrm{~nm}$ every $24 \mathrm{~h}$ for a duration of $120 \mathrm{~h}$.

\section{Thermal degradation kinetics}

The ability of natural pigments to retain their color when exposed to thermal processes remains a major challenge in food processing. Undesirable visual color and degradation of pigment structure was found to affect sensory attributes. Natural red pigments such as anthocyanins, lycopene and betacyanins have health promoting compounds (Leong et al., 2018). Most natural pigments depict color stability below $50^{\circ} \mathrm{C}$ and were observed to begin degrading when exposed to 
temperatures exceeding $50^{\circ} \mathrm{C}$. A study conducted by Herbach et al. (2006), depicted that betalains when heated above temperatures exceeding $50^{\circ} \mathrm{C}$, display rapid loss in color, which make their use as food colorants unsuitable. Thermal degradation of prodigiosin was carried out according to method by FernándezLópez et al. (2013). Crude pigment (100 mg/L methanol) was thermally heated in a water bath at temperatures of 50,70 and $90^{\circ} \mathrm{C}$ for $5 \mathrm{~h}$. The absorbance was monitored at $533 \mathrm{~nm}$. After heating, the samples were placed in an ice bath to cool in order to facilitate a stop in thermal degradation. Absorbance was recorded for the samples and the thermal degradation was calculated as follows (Equation 3) using a method established by Van den Broeck et al. (1998).

$$
\ln =\frac{A i}{A o}-k t
$$

Where, $A$ denotes residual absorbance after treatment,

$A_{0}$ is initial absorbance,

$t$ and $k$ represent time in hours

Reaction rate constant $(h-1)$ at a specific temperature

Half -life values were determined by plotting $A_{0} / A$ ratio vs the thermal period of heating.

\section{Colorimetry Evaluation of pigment}

The colorimetry assay was determined utilizing method by Fernández-López et al. (2013). Color was monitored using the CIELab parameters. The parameters were obtained using a colorimetric reader. The differences in $\Delta \mathrm{E}=\left[\left(\Delta \mathrm{L}^{*}\right)^{2}+\left(\Delta \mathrm{a}^{*}\right)^{2}+\right.$ $\left.\left(\Delta \mathrm{b}^{*}\right)^{2}\right]^{1 / 2}$ between the sample and a red synthetic standard.

\section{Results and discussions}

\section{Growth of Serratia marcescens strain}

The culture was monitored over a $24 \mathrm{~h}$ period at a temperature of $28^{\circ} \mathrm{C}$ to observe when pigment production becomes visible and to establish factors influencing the production of pigment.

The pigment prodigiosin produced by $S$. marcescens can be classified as a secondary metabolite. Figure 1 reveals the multiplication dynamics of bacterial cells which correlates to the synthesis of prodigiosin. As discussed by Bu" Lock et al. (1965), the maximum production occurs in the stationary growth phase. Growth and synthesis of the pigment usually occur in two distinctive phases, namely the trophic phase said to be the nourishment phase which enhances cellular growth and the idiophase which is the individual phase, a period in which secondary metabolites, in this case prodigiosin, is produced. Growth can be influenced by factors such as temperature and carbon/nitrogen sources which assist in the regulation of the production of the pigment. Characteristically prodigiosin production is regulated in senescent cells during the stationary phase. Serratia marcescens is known to produce characteristic bright red colonies (Shalinimol, 2012). 


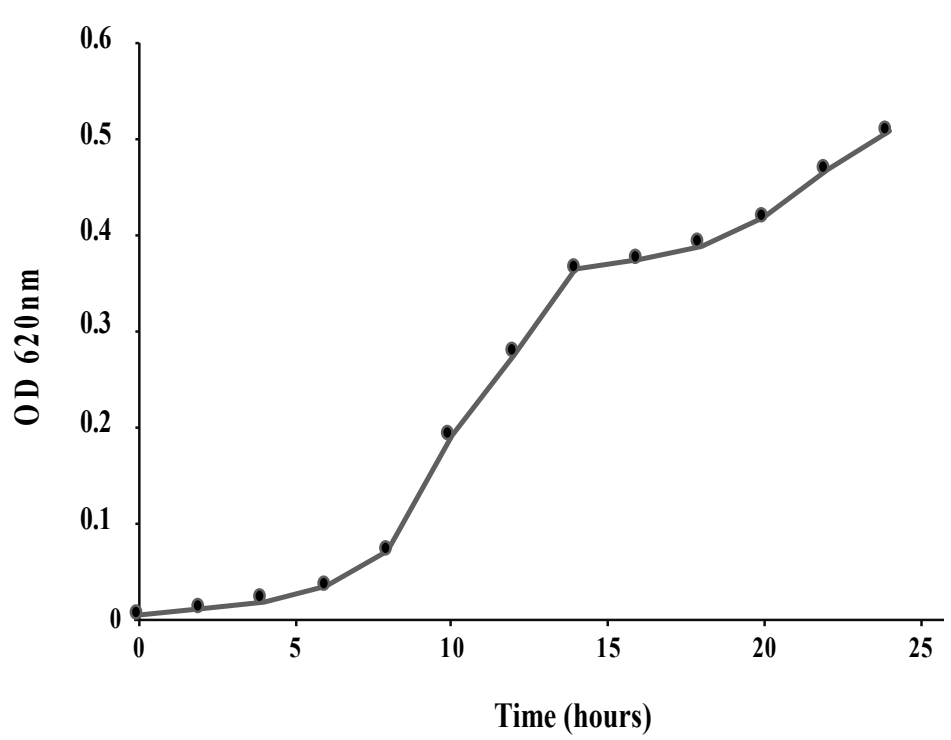

Figure 1. Growth curve of Serratia marcescens strain

Prodigiosin pigment produced by bacteria $S$. marcescens was suggested to develop deep red color when the culture is aged (older than 8 days) and media possesses glycerol (oil) (Shalinimol, 2012). In order for $S$. marcescens to develop and yield the desired deep red pigment a low phosphate and glucose media is required (Venil and Lakshmanaperumalsamy, 2009). Although specific synthetic media was developed and utilised for the cultivation of $S$. marcescens growth and prodigiosin production, many studies conducted thus far have facilitated cultivation in media such as nutrient broth, maltose broth, lysogeny broth and peptone glycerol broth (Giri et al., 2004).

\section{Optimization of prodigiosin}

There are various factors that influence the production of prodigiosin, such factors include incubation temperature, $\mathrm{pH}$, duration of incubation and selective media which were simultaneously examined (Figure 2).

\section{Media Composition}

Nutrients are required by microorganism as an energy source enhancing growth and reproducibility. This study examined prodigiosin production in nutrient broth $(\mathrm{Nb})$ and lysogeny broth $(\mathrm{Lb})$. As seen in Figure $2 \mathrm{c}$ there was a significant increase in prodigiosin production (1332.67 units/cell) in $\mathrm{Lb}$ broth at $25^{\circ} \mathrm{C}$, for $120 \mathrm{~h}$. As seen in Figure 2, prodigiosin production occured during the stationary phase in both $\mathrm{Lb}$ broth and $\mathrm{Nb}$ broth. The results obtained in Figure $2 \mathrm{c}$ correspond to similar results obtained in a study conducted by Ramani et al. (2014). One of the proposed reasons as to why pigment production is significant higher in Lb broth rather than nutrient broth is due to the composition of nutritional ingredients. 


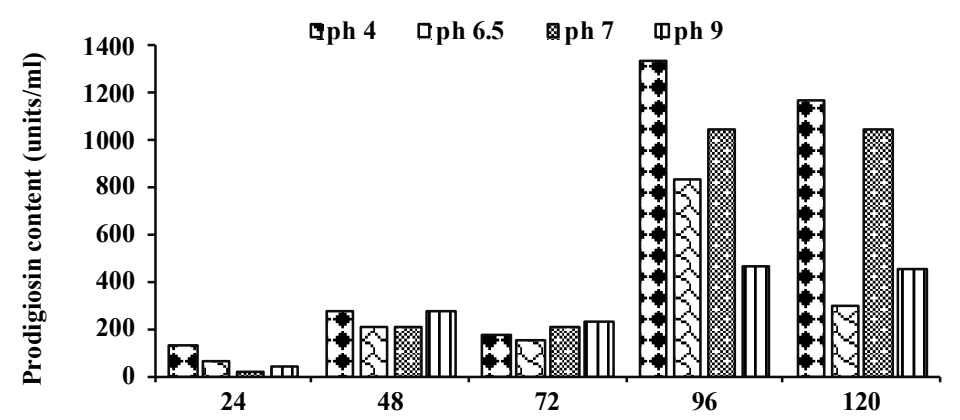

a)

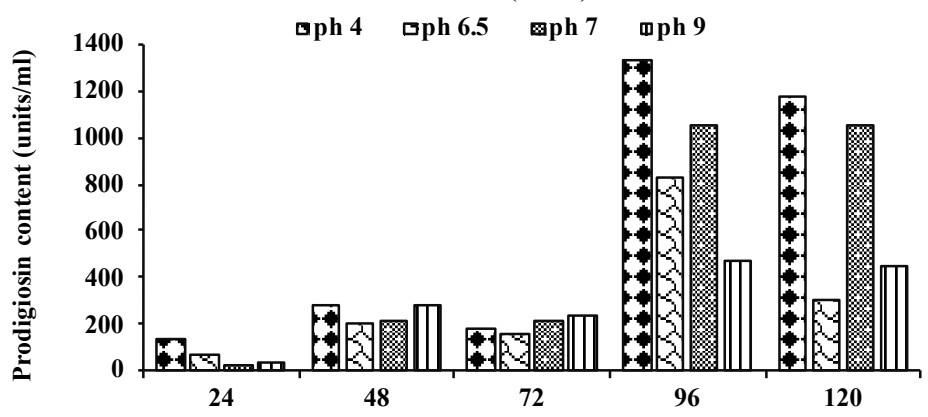

b)

Time (hours)

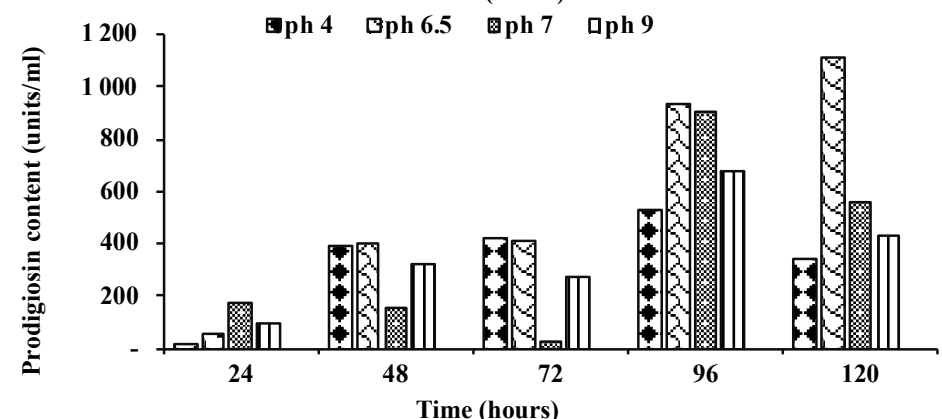

c)

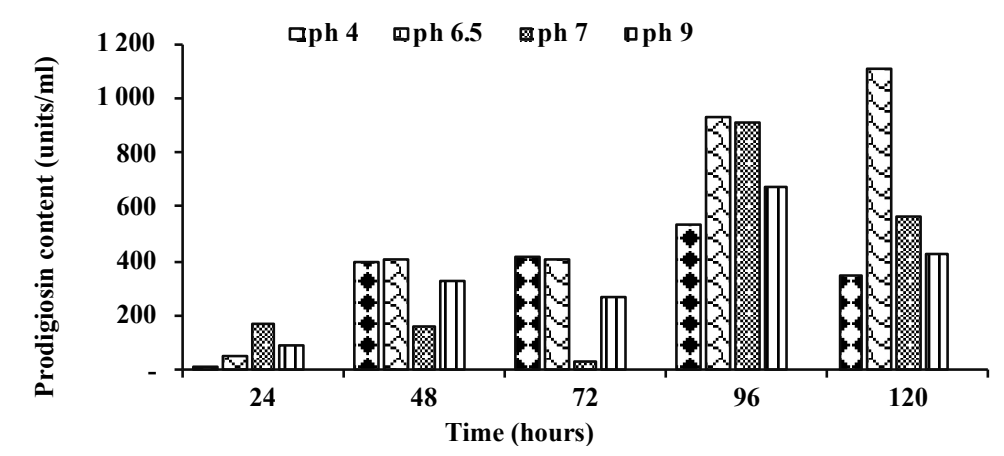

d)

Figure 2. Optimization of prodigiosin production by varying combined stress factors. Bars denote mean \pm standard deviation $(\mathrm{n}=3)$. a) $S$. marcescens in nutrient broth $(\mathrm{Nb})$ at $25^{\circ} \mathrm{C}$; b) $S$. marcescens in nutrient broth $(\mathrm{Nb})$ at $30^{\circ} \mathrm{C}$; c) $S$. marcescens in lysogeny broth $(\mathrm{Lb})$ at $25^{\circ} \mathrm{C}$; d) $S$. marcescens in lysogency broth $(\mathrm{Lb})$ at $30^{\circ} \mathrm{C}$. 
Compounds that serve as carbon source, nitrogen source and inorganic salts are influencing factors in pigment production. Typical nutrient broth contains peptone, meat extract, sodium chloride $(\mathrm{NaCl})$, and glucose in comparison to $\mathrm{Lb}$ media which contains tryptone, yeast extract and $\mathrm{NaCl}$. Tryptone and yeast extract in $\mathrm{Lb}$ media are sources of nitrogen which highly influence the growth of cells as well as pigment production of prodigiosin. Trypton encourages higher metabolic activity increasing pigment production (Wei and Chen, 2005). A study conducted by Gulani et al. (2012), established that the role of glucose in production of prodigiosin was critical. Glucose being the carbon source in $\mathrm{Nb}$ broth was found to produce relatively lower yield. Glucose was suggested to inhibit pigment production as it causes acidification of the media. The relatively lower yield in prodigiosin production is due to the presence or addition of glucose which has also been reported by various other studies (Oller, 2005; Gulani et al., 2012).

Growth rates and robust prodigiosin production is well supported by $\mathrm{Lb}$ medium. Wei and Chen (2005) further went on to describe that increase in prodigiosin production can be facilitated by modification of the composition of Lb media. It was found, when tryptone and yeast extract were increased, that there was a profound increase in pigment yield, especially when sodium chloride $(\mathrm{NaCl})$ levels were reduced, suggesting that $\mathrm{NaCl}$ may pose an inhibitory effect on pigment production. The presence of excessive $\mathrm{NaCl}$ concentrations are said to stop or slow down the activity of condensing enzymes which is responsible in the regulation of the terminal condensation step in prodigiosin production (Silverman and Munoz, 1973).

\section{pH}

$\mathrm{pH}$ influences production of prodigiosin by either affecting the nutritional properties of the media such as the solubility of the nutrients, transportation, and ionization, in addition to influencing the overall stability of the pigment. Maximum production of prodigiosin (1332.67 unit/cell) was observed at $\mathrm{pH} 6.5 \mathrm{in} \mathrm{Lb}$ broth at $120 \mathrm{~h}$. As seen in Figure 2c prodigiosin is also capable of being synthesized at $\mathrm{pH}$ 7 which was reported in many studies. The $\mathrm{pH}$ range supporting the production of prodigiosin was reported to be between 5 to 8 (Das et al., 2018), however as seen in Figure 2a and 2d, S. marcescens in $\mathrm{Nb}$ broth at $\mathrm{pH} 4$ also produces prodigiosin at varying lower levels. It was suggested that, when the selected media becomes too acidified, an inhibitory effect limits the use of the carbon source. This causes a reduction in levels of prodigiosin production (Sole et al., 1997). This can be observed in Figure $2 \mathrm{~b}$ and $2 \mathrm{~d}$. A similar effect is observed when there is an increase in alkalinity of media, which results in decrease of cell viability and production of prodigiosin (Das et al., 2018). It may be concluded that $\mathrm{pH}$ is a determining factor contributing to either an increase or decrease in prodigiosin yield.

\section{Duration of pigment production}

Maximum prodigiosin production was previously reported to occur in the $96 \mathrm{~h}$ in a study conducted by Ramani et al. (2014). The present study revealed that maximum production of pigment was observed after $96 \mathrm{~h}$, as seen in Figure 2c. 
This result was supported by the commencing of an increase in pigment production which was observed to occur towards the stationary growth phase, and the quantity of pigment reached peaks after 4 days of incubation which can be observed in Figure 2. According to a study conducted by Williams (1973), following $24 \mathrm{~h}$ of incubation there was little increase in cells. Between 48 and $96 \mathrm{~h}$ maximal production of prodigiosin occurs due to the end of exponential phase. It was observed that prodigiosin production generally occurs at the end of exponential growth phase, during the more stationary growth phase where cells cease to divide (senescent cells). A study conducted by Elkenawy et al. (2017) revealed that incubation period $\geq 6$ days produced better yield of prodigiosin and the pigment appeared brighter and intensified.

\section{Temperature}

Temperature is a critical factor, although microorganism may be supplied with the necessary nutrients, its growth is highly dependent on the incubation temperature. The temperature determines and influences the cells ability to absorb nutrients required for production of pigment and also influences the degradation and denaturing of cells. Figure $2 \mathrm{a}$ and $2 \mathrm{~b}$ shows that $S$. marcescens incubated at a temperature of $25^{\circ} \mathrm{C}$, at varying $\mathrm{pH}$ produced quantitatively higher prodigiosin in comparison to cultivation at $30^{\circ} \mathrm{C}$ as seen in Figure $2 \mathrm{c}$ and $2 \mathrm{~d}$. The growth of most bacteria are facilitated at a temperature of $37^{\circ} \mathrm{C}$, however in $S$. marcescens at $37^{\circ} \mathrm{C}$ the growth of bacteria is favored over the production of pigment. Various studies showed that at temperatures higher than $30^{\circ} \mathrm{C} \mathrm{S}$. marcescens appeared white and there was a complete block in prodigiosin production (Haddix and Werner, 2000; Sundaramoorthy et al., 2009). The white pigment, which is suggested to be nonprofiling, could be a response to a lost in activity of enzymes that assist in producing the distinctive red color. Biosynthesis was established over a narrow temperature range of 24 to $30^{\circ} \mathrm{C}$ (Casullo de Araújo et al., 2010).

\section{Extraction of pigment}

Extraction was successfully carried out by the use of $95 \%$ methanol. The pigment extracted in the solvent did not display a change in color when dissolved. In a study conducted by Vora et al. (2014) was examined the extraction of the pigment with different solvents including chloroform, ethyl acetate, acetone and methanol. Acetone and methanol proved to have the capacity to extract the pigment from the cell, however the largest extraction of the pigment was shown to be achieved in methanol. A presumptive test was carried out on the extracted pigment, to qualitatively determine if the pigment extracted was prodigiosin. A sharp pink color change was observed upon the addition of $1 \mathrm{M} \mathrm{HCl}$ and a distinguishing yellow when $1 \mathrm{M}$ of $\mathrm{NaOH}$ was added. Both indicated a positive result. This corresponded to results obtained in a study by Gulani et al. (2012).

\section{Spectral analysis and TLC purification}

The pigment was subjected to spectral analysis and the maximum wavelength at which prodigiosin peaked was at $533 \mathrm{~nm}$, which corresponded to results reported by Nakashima et al. (2005). The spectrophotometric data obtained for the red 
pigment complex was in agreement with most studies conducted. The wavelength range where prodigiosin was reported to peak was 499, 530, 533 and $535 \mathrm{~nm}$. However it was also found to be very depended on the solvent utilized for the extraction of the pigment. The purification was carried out using the solvent system chloroform:methanol $(95: 5 \mathrm{v} / \mathrm{v})$. The $\mathrm{Rf}$ value obtained was 0.875 which corresponded to results obtained by Vora et al. (2014) who also obtained various shades of fractions such as green, blue, yellow and dark orange with respectively different $\mathrm{Rf}$ values.

Bunting (1940) also suggested the presence of purple fractions, resulting from the purification of prodigiosin. These different fractions are most often a result of the elution solvents as well as also the type of strain isolate.

\section{Stability of extracted pigment}

pH stability of prodigiosin

Upon the addition of the respective buffers a color change was noted - from red to pink in acidic condition and from red to yellow as the $\mathrm{pH}$ increased. Alkaline conditions lead to faster reduction in prodigiosin stability as seen in Figure 3 at $\mathrm{pH}$ 11. These color changes corresponded to a study conducted by Namazkar and Ahmad (2013). At extreme acidic $\mathrm{pH}$, the protonation of pyrrole group occurs on one of the carbon atoms of the second position in the ring and not on nitrogen atom, therefore becoming nonaromatic (Struchkova et al., 1973). Fading in prodigiosin is caused by this protonation. In extreme alkaline $\mathrm{pH}$, the $\mathrm{OH}$ - groups deprotonates the amine group in the structure thus resulting in the formation of an anion. Both conditions proceed to destroy the very conjugated system of double bonds and hence being responsible for pigment degradation (Namazkar et al., 2013). As mentioned upon the addition of the respective buffers there was an immediate color change. It was observed that in conjunction to a color change the spectral peak of prodigiosin changed and depicted various peaks as seen in Figure 4. This was in agreement to a study conducted by Faraag et al. (2017). It is suggested that prodigiosin exists in two dissimilar forms. However, this is dependent on the hydrogen ion concentration of the solution. A sharp spectral peak within the range of $535 \mathrm{~nm}$ was observed when the pigment was subjected to acidic conditions, further acidic conditions leading to the pigment depicting a spectral peak at $510 \mathrm{~nm}$. The pigment exhibited orange to yellow color in alkaline conditions peaking at $470 \mathrm{~nm}$ as discussed by idem.

\section{Evaluation of prodigiosin stability to light}

Chemical mechanisms that trigger fading of color are highly depended on the pigments nature. Oxidation, a combination of oxidation and hydration, and metal ion loss and oxidation are accelerated when pigments are exposed to light irradiation. As seen in Figure 5, when prodigiosin was irradiated with light there was significant reduction in stability over the respective duration as compared to when prodigiosin was kept in the absence of light. A gradual reduction in pigment stability when exposed to light was also reported by Namazkar and Ahmad (2013). In the presence of light, the pigment molecules are described as excited and in an 
energetic state suitable to increase their ability to react. This reaction leads to the destruction of color due to the delocalization of the pyrrole group in prodigiosin, which contributes to the characteristic reddish color.

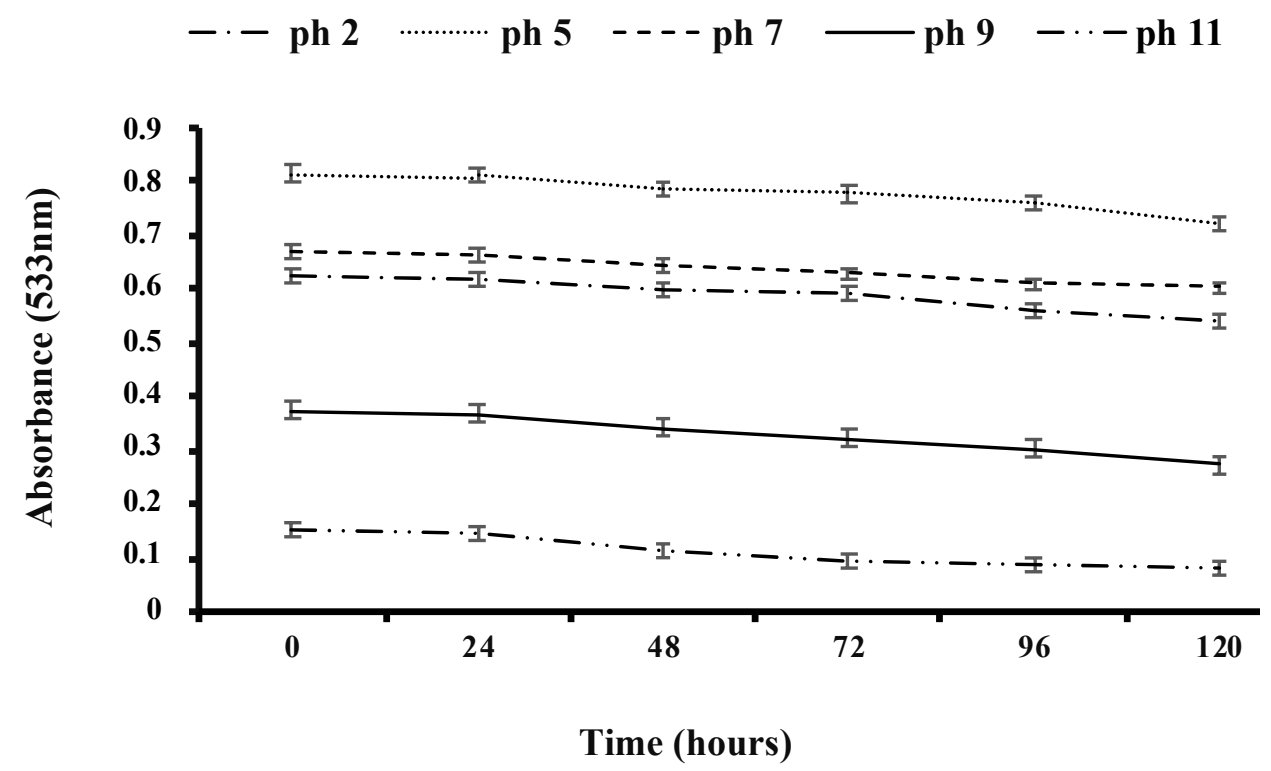

Figure 1. Gradual reduction in $\mathrm{pH}$ stability of crude prodigiosin pigment upon the addition of respective buffers. Data represents mean \pm standard deviation $(n=3)$.

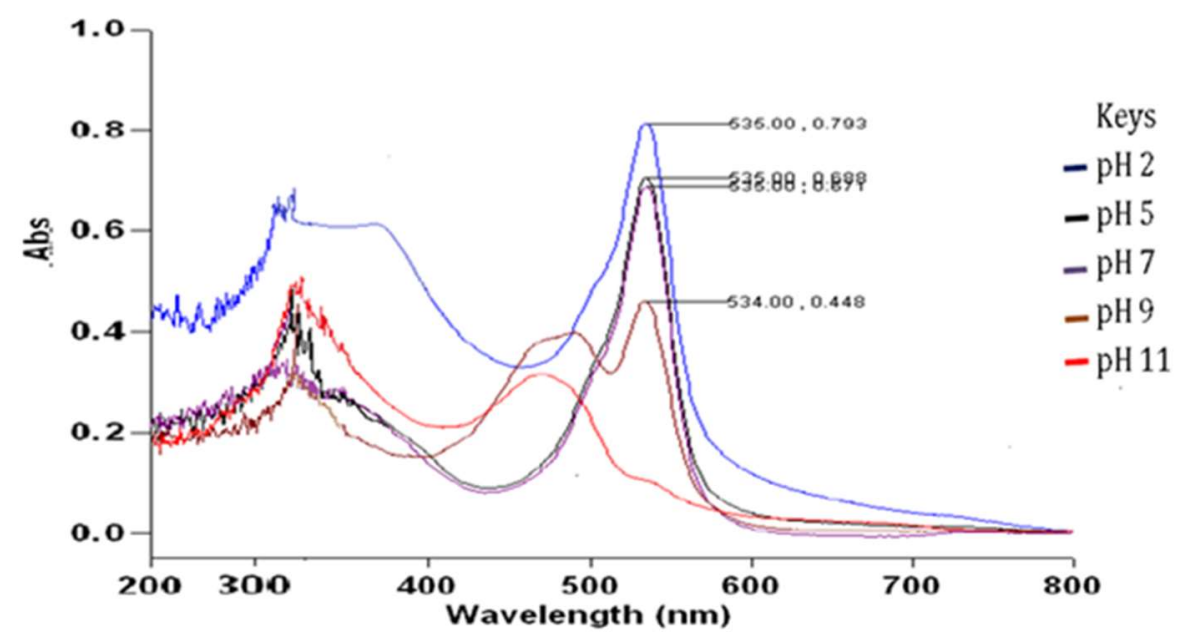

Figure 2. Spectral peaks presented by prodigiosin at various $\mathrm{pH}$ values 


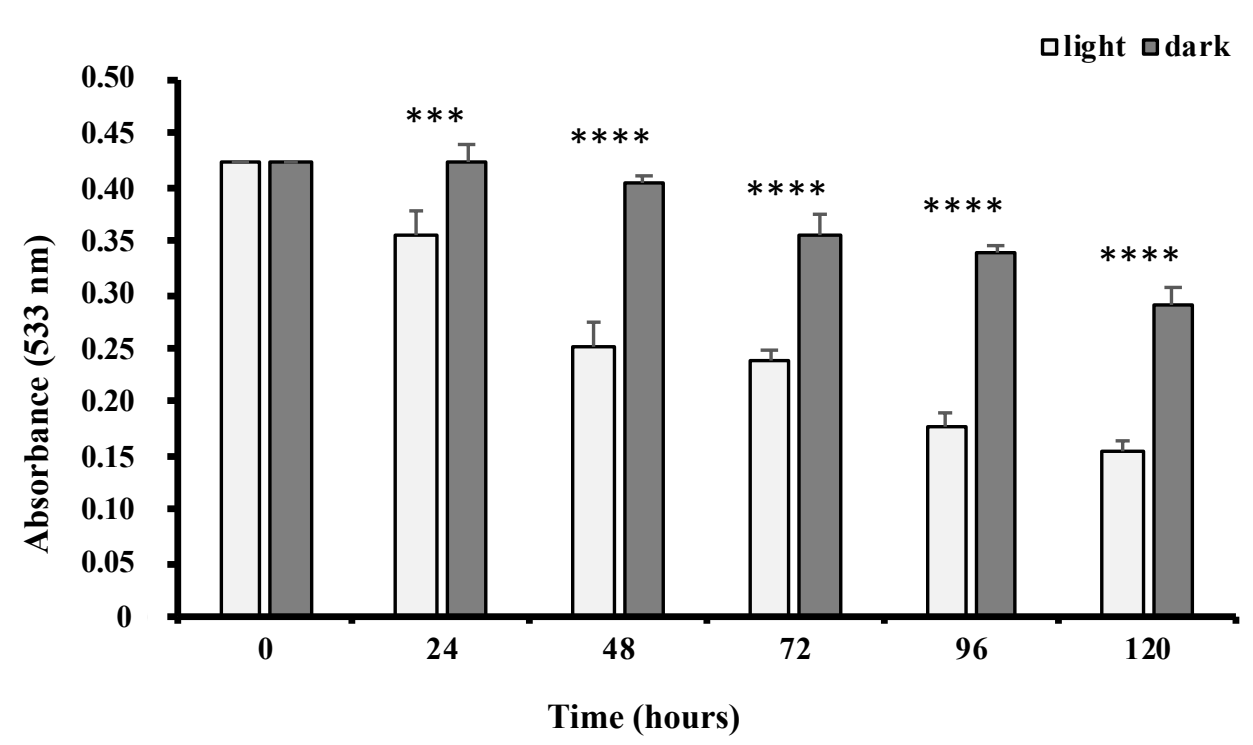

Figure 3. Effect of light exposure on prodigiosin stability. Bars denote mean \pm standard deviation $(\mathrm{n}=3)$.

\section{Evaluation of temperature on prodigiosin stability}

Prodigiosin is fairly stable over a temperature of $20-60^{\circ} \mathrm{C}$ as seen in Figure 6 . However, as the temperature increased a reduction in color stability was observed. This reduction in color could be due to the supposed destruction of pyrrole groups forming part of the prodigiosin structure. Temperature reduction was observed due to the high sensitivity of the monopyrrole and bipyrrole (Williams, 1973). These results were in correspondence to a study conducted by Rocha et al. (2012). The instability of natural extracted pigment to temperature often results to the alteration of their chemical structures which thereafter poses an effect on their absorption spectra as well as their color properties (Fernández-López et al., 2013).

\section{Thermal degradation kinetics}

As seen in Figure 7 direct relationship can be observed between the temperature and the pigment stability: as the temperature increases, the pigment stability is reduced. In a study conducted by Fernández-López et al. (2013), it was suggested that degradation pattern was highly dependent on temperature and time. Observations made suggest that high thermal conditions bring about visible reduction color changes in the pigment. 


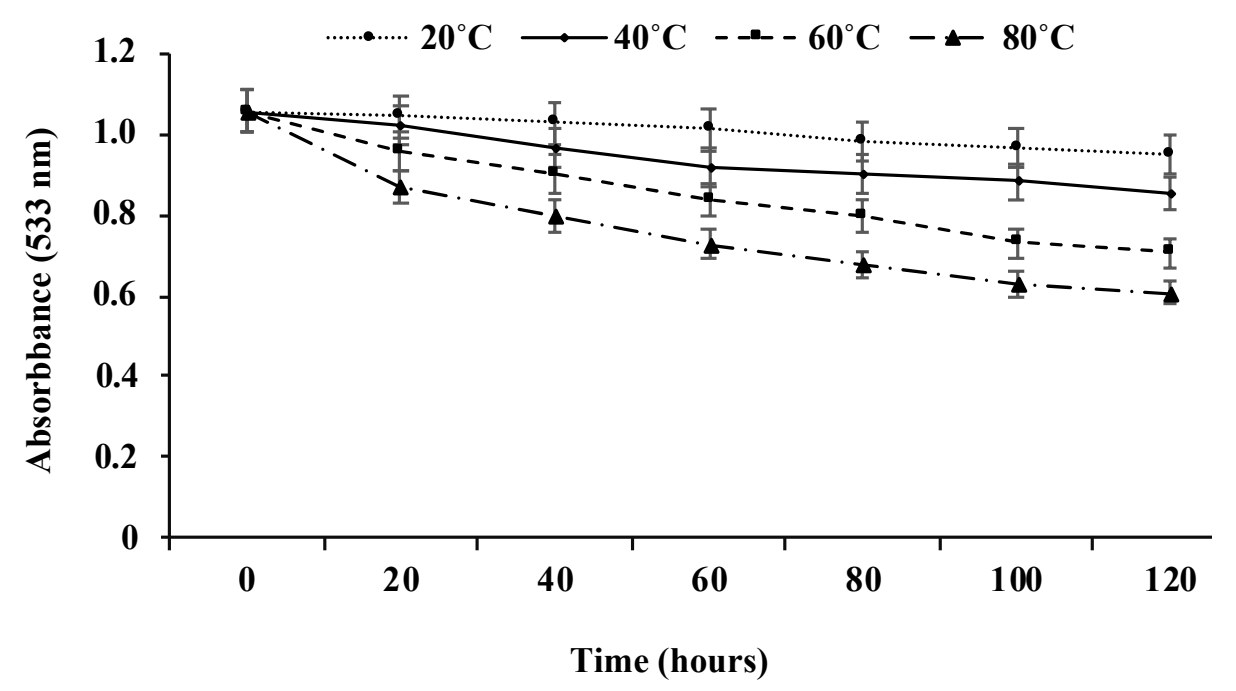

Figure 4. Prodigiosin stability at various temperature range over time. Data represents mean \pm standard deviation $(n=3)$.

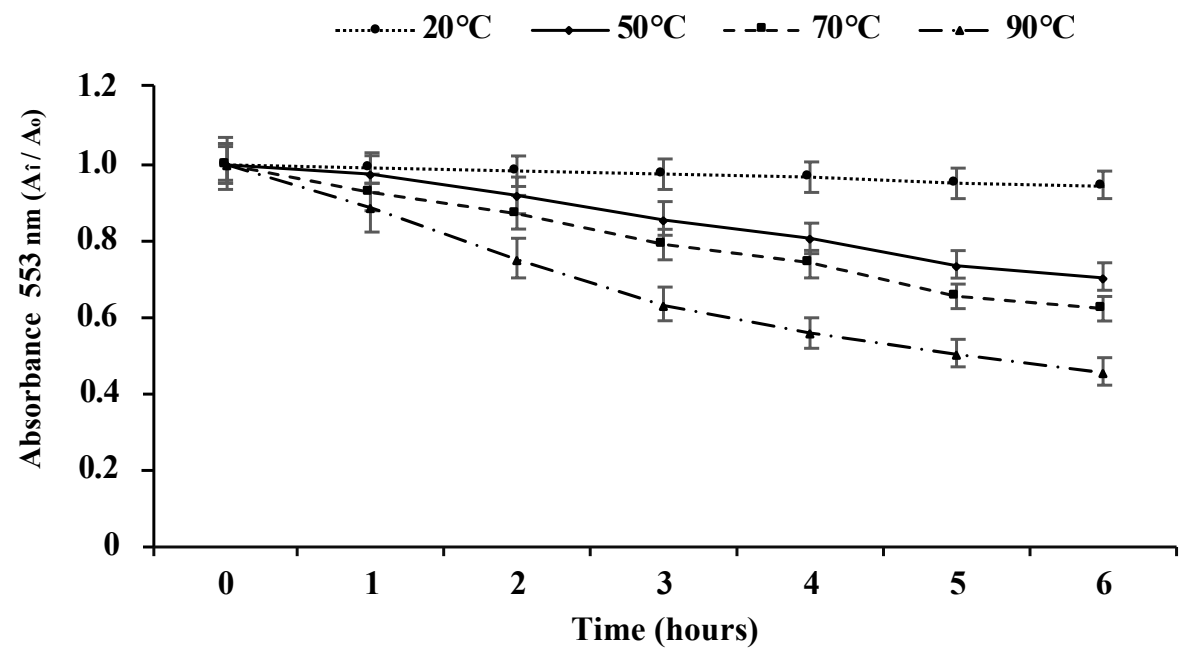

Figure 5. Thermal degradation of prodigiosin at $20,50,70$ and $90^{\circ} \mathrm{C}$.

Data represents mean \pm standard deviation $(n=3)$.

\section{Colorimetric evaluation of prodigiosin}

According to Whetzel (2015), $\Delta \mathrm{L}^{*}$ value represents lightness vs. darkness, $\Delta \mathrm{a}^{*}$ value represents the level of redness to greenness, and $\Delta b^{*}$ value is an indication of yellowness versus blueness. The $\mathrm{LAB}$ values are parameters which are indication of the overall difference in color between the sample and standard $(\Delta \mathrm{E}) . \Delta \mathrm{E}$ is an overall color difference that classifies the sample as either a pass or fail. When $\Delta \mathrm{L}^{*}$ is lower than 50, the sample is regarded as being dark, when higher (51-100), the sample is classified as being light. As seen in Table 1, prodigiosin presented a low 
$\Delta \mathrm{L}^{*}$ value $(1.11 \pm 0.5)$, indicating that prodigiosin is darker. The $\Delta \mathrm{a}^{*}$ value $(0.87 \pm 0.07)$ indicated that prodigiosin was overall red, while $\Delta \mathrm{b}^{*}$ value indicated that prodigiosin $(1.40 \pm 0.9)$ had more yellowness. The overall color difference between prodigiosin and the standard was 0.2 . Whetzel (2015) suggested that when $\Delta \mathrm{E} \leq 1$, the sample is closely related to the standard. $\Delta \mathrm{E}$ value generally range from 0 to 100 . In this case the difference showed that prodigiosin was closely related to the standard.

Table 1. Clorimetric analysis of prodigiosin in comparison to a commercial synthetic red colorant

\begin{tabular}{lcccc}
\hline & $\Delta \mathrm{L}^{*}$ & $\Delta \mathrm{a}^{*}$ & $\Delta \mathrm{b}^{*}$ & $\Delta \mathrm{E}$ \\
\hline Prodigiosin & $1.11 \pm 0.5$ & $0.87 \pm 0.07$ & $1.40 \pm 0.9$ & 1.98 \\
Ponceau 4R (Standard) & $1.22 \pm 0.03$ & $1.44 \pm 0.005$ & $0.07 \pm 0.01$ & 1.78 \\
\hline
\end{tabular}

Data represents mean \pm standard deviation $(\mathrm{n}=3)$

\section{Conclusions}

Like all naturally sourced pigments, prodigiosin also depicted gradual reduction in stability parameters such as $\mathrm{pH}$, light and temperature. The color degradation observed in prodigiosin can be attributed to the destruction of its natural chemical structure. However, this study does not condone the use of prodigiosin in foods as a potential natural colorant. Modification of prodigiosins chemical structure or methods such as encapsulation of the colorant could support its addition to foods.

\section{References}

Boger, D.L., Patel, M. 1988. Total synthesis of prodigiosin, prodigiosene, and desmethoxyprodigiosin: Diels-Alder reactions of heterocyclic azadienes and development of an effective palladium (II)-promoted 2,2'-bipyrrole coupling procedure. The Journal of Organic Chemistry, 53(7), 1405-1415.

Boone, D.R., Castenholz, R.W. 2001. Bergey's Manual of Systematic Bacteriology. Springer-Verlag, New York

Bu" Lock, J.D., Hamilton, D., Hulme, M.A., Powell, A.J., Smalley, H.M., Shepherd, D. Smith, G.N. 1965. Metabolic development and secondary biosynthesis in Penicillium urticae. Canadian Journal of Microbiology, 11(5), 765-778.

Bunting, M.I. 1940. A description of some color variants produced by Serratia marcescens, strain 274. Journal of Bacteriology, $\mathbf{4 0}(1), 57$.

Casullo de Araújo, H.W., Fukushima, K. and Takaki, G.M.C. 2010. Prodigiosin production by Serratia marcescens UCP 1549 using renewable - resources as a low cost substrate. Molecules, 15(10), 6931-6940.

Chandran, J., Nisha, P., Singhal, R.S. and Pandit, A.B. 2014. Degradation of colour in beetroot (Beta vulgaris L.): a kinetics study. Journal of Food Science and Technology, 51(10), 2678-2684.

Dabas, D., Kean, G. 2014. Red natural colors for high pH applications. Advances In Food Technology and Nutritional Sciences - Open Journal, 1(1), 10-16. 
Das, P.K., Samal, S., Sahoo, R. and Sabat, P.K. 2018. Resistance of Serratia marcescens (SPKD15) to various environmental stress conditions: Effect on cell viability and prodiogisin production. PharmaTutor, 6(4), 18-26.

Ding, M.J., Williams, R.P. 1983. Biosynthesis of prodigiosin by white strains of Serratia marcescens isolated from patients. Journal of Clinical Microbiology, 17(3), 476-480.

Dufossé, L., Galaup, P., Yaron, A., Arad, S.M., Blanc, P., Murthy, K.N.C. Ravishankar, G.A. 2005. Microorganisms and microalgae as sources of pigments for food use: a scientific oddity or an industrial reality?. Trends in Food Science \& Technology, 16(9), 389-406.

El-Bialy, H.A., El-Nour, S.A.A. 2015. Physical and chemical stress on Serratia marcescens and studies on prodigiosin pigment production. Annals of Microbiology, 65(1), 59-68.

Elkenawy, N.M., Yassin, A.S., Elhifnawy, H.N. Amin, M.A. 2017. Optimization of prodigiosin production by Serratia marcescens using crude glycerol and enhancing production using gamma radiation. Biotechnology Reports, 14, 47-53.

Faraag, A.H., El-Batal, A.I. El-Hendawy, H.H. 2017. Characterization of prodigiosin produced by Serratia marcescens strain isolated from irrigation water in Egypt. Natural Science, 15, 55-68.

Fernández-López, J.A., Angosto, J.M., Giménez, P.J. León, G. 2013. Thermal stability of selected natural red extracts used as food colorants. Plant Foods for Human Nutrition, 68(1), 11-17.

Giri, A.V., Anandkumar, N., Muthukumaran, G. Pennathur, G. 2004. A novel medium for the enhanced cell growth and production of prodigiosin from Serratia marcescens isolated from soil. BMC Microbiology, 4(1), 11.

Gulani, C., Bhattacharya, S. Das, A. 2012. Assessment of process parameters influencing the enhanced production of prodigiosin from Serratia marcescens and evaluation of its antimicrobial, antioxidant and dyeing potentials. Malaysian Journal of Microbiology, 8(2), 116-122.

Haddix, P.L., Werner, T.F. 2000. Spectrophotometric assay of gene expression: Serratia marcescens Pigmentation. Bioscene, 26, 3-13.

Herbach, K.M., Stintzing, F.C. Carle, R. 2006. Betalain stability and degradationstructural and chromatic aspects. Journal of Food Science, 71(4), R41-R50.

Khanafari, A., Assadi, M.M. Fakhr, F.A. 2006. Review of prodigiosin, pigmentation in Serratia marcescens. Online Journal of Biological Sciences, 6(1), 1-13.

Kumar, A., Vishwakarma, H.S., Singh, J., Dwivedi, S. Kumar, M. 2015. Microbial Pigments: Production and their Applications in Various Industries. International Journal of Pharmaceutical, Chemical \& Biological Sciences, 5(1), 203-212.

Leong, H.Y., Show, P.L., Lim, M.H., Ooi, C.W. Ling, T.C. 2018. Natural red pigments from plants and their health benefits: A review. Food Reviews International, 34(5), 463-482.

Malik, K., Tokkas, J., Goyal, S. 2012. Microbial pigments: a review. International Journal of Microbial Resource Technology, 1(4), 361-365.

Mekhael, R., Yousif, S.Y. 2009. The role of red pigment produced by Serratia marcescens as antibacterial and plasmid curing agent. Journal of Duhok University, 12(1), 268-274.

Montaner, B., Navarro, S., Piqué, M., Vilaseca, M., Martinell, M., Giralt, E., Gil, J., PérezTomás, R. 2000. Prodigiosin from the supernatant of Serratia marcescens induces apoptosis in haematopoietic cancer cell lines. British Journal of Pharmacology, 131(3), 585-593. 
Moraes, C.S., Seabra, S.H., Albuquerque-Cunha, J.M., Castro, D.P., Genta, F.A., de Souza, W., Brazil, R.P., Garcia, E.S., Azambuja, P. 2009. Prodigiosin is not a determinant factor in lysis of Leishmania (Viannia) braziliensis after interaction with Serratia marcescens d-mannose sensitive fimbriae. Experimental Parasitology, 122(2), 84-90.

Nachay, K. 2014. Developing coloring solutions naturally. Food Technology Magazine, 68(3), 56 .

Nakashima, T., Kurachi, M., Kato, Y., Yamaguchi, K., Oda, T. 2005. Characterization of bacterium isolated from the sediment at coastal area of Omura bay in Japan and several biological activities of pigment produced by this isolate. Microbiology and Immunology, 49(5), 407-415.

Namazkar, S., Ahmad, W.A. 2013. Spray-dried prodigiosin from Serratia marcescens as a colorant. Biosciences Biotechnology Research Asia, 10(1), 69-76.

Namazkar, S., Garg, R., Ahmad, W.Z., Nordin, N. 2013. Production and characterization of crude and encapsulated prodigiosin pigment. International Journal of Chemical Sciences and Applications, 3, 116-129.

Oller, A.R. 2005. Media effects of sugars on pigmentation and antibiotic susceptibility in Serratia marcescens. Transactions of the Missouri Academy of Science, 39, 11-15.

Ramani, D., Nair, A., Krithika, K. 2014. Optimization of cultural conditions for the production of prodigiosin by Serratia marcescens and screening for the antimicrobial activity of prodigiosin. International Journal of Pharmacology and Biological Sciences, 5(3), 383-392.

Rocha, G.A., Fávaro-Trindade, C.S., Grosso, C.R.F. 2012. Microencapsulation of lycopene by spray drying: characterization, stability and application of microcapsules. Food and Bioproducts Processing, 90(1), 37-42.

Shalinimol, C.R. 2012. Production of pink pigment by a newly isolated Serratia marcescens bacterium from coir pith water and application in dyeing industry by response surface methodology. Manonmaniam Sundaranar University.

Silverman, M.P., Munoz, E.F. 1973. Effect of iron and salt on prodigiosin synthesis in Serratia marcescens. Journal of Bacteriology, 114(3), 999-1006.

Sole, M., Francia, A., Rius, N., Loren, J.G. 1997. The role of pH in the 'glucose effect' on prodigiosin production by non-proliferating cells of Serratia marcescens. Letters in Applied Microbiology, 25(2), 81-84.

Struchkova, M.I., Dvoryantseva, G.G., Belova, T.P., Sklyar, Y.E. Evstigneeva, R.P. 1973. Protonation of acetyl and formyl derivatives of pyrrole. Chemistry of Heterocyclic Compounds, 9(11), 1355-1360.

Sundaramoorthy, N., Yogesh, P., Dhandapani, R., 2009. Production of prodigiosin from Serratia marcescens isolated from soil. Indian Journal of Science and Technology, 2(10), 32-34.

Suryawanshi, R.K., Patil, C.D., Borase, H.P., Salunke, B.K., Patil, S.V. 2014. Studies on production and biological potential of prodigiosin by Serratia marcescens. Applied biochemistry and Biotechnology, 173(5), 1209-1221.

Van den Broeck, I., Ludikhuyze, L., Weemaes, C., Van Loey, A., Hendrick, M. 1998. Kinetics for isobaric- isothermal degradation of 1-ascorbic acid. Journal of Agricultural and Food Chemistry, 46(5), 2001-2006.

Venil, C.K. Lakshmanaperumalsamy, P. 2009. An insightful overview on microbial pigment, prodigiosin. Electronic Journal of Biology, 5(3), 49-61. 
Vora, J.U., Jain, N.K. Modi, H.A. 2014. Extraction, Characterization and application studies of red pigment of halophile Serratia marcescens KH1R KM035849 isolated from Kharaghoda soil. International Journal of Pure \& Applied Bioscience, 2(6), 160-168.

Wei, Y.H., Chen, W.C. 2005. Enhanced production of prodigiosin-like pigment from Serratia marcescens $\mathrm{SM} \Delta \mathrm{R}$ by medium improvement and oil-supplementation strategies. Journal of Bioscience and Bioengineering, 99(6), 616-622.

Whetzel N. 2012. Measuring Color using Hunter L, a, b versus CIE 1976 L*a*b. Hunter Associates Laboratory, AN 1005.00: 1-4.

Williams, R.P. 1973. Biosynthesis of prodigiosin, a secondary metabolite of Serratia marcescens. Applied Environmental Microbiology, 25(3), 396-402.

Williams, R.P., Gott, C.L., Qadri, S.H., Scott, R.H. 1971. Influence of temperature of incubation and type of growth medium on pigmentation in Serratia marcescens. Journal of Bacteriology, 106(2), 438-443. 